\title{
Presence of Epidermal-derived Thymocyte Activating Factor/Interleukin 1 in Normal Human Stratum Corneum
}

\author{
Lorise C. Gahring, Anne Buckley, and Raymond A. Daynes \\ Department of Pathology, University of Utah School of Medicine, Salt Lake City, Utah 84132
}

\begin{abstract}
Keratinocytes produce a molecule, epidermal-derived thymocyte activating factor (ETAF), which is biologically and physiochemically similar to the polypeptide hormone interleukin 1 (IL-1). Because the stratum corneum (SC) is composed of terminally differentiated keratinocytes, we questioned whether ETAF/IL-1 could be isolated from this tissue. The extraction of normal human SC with a physiologic saline solution yielded a large amount of ETAF/IL-1 activity, as measured by the in vitro thymocyte co-stimulator assay. SC-derived ETAF/IL-1 (scETAF/IL-1) eluted from a sizing column with an approximate molecular weight of 15,000 , and demonstrated three isoelectric point forms after separation on a chromatofocusing column. By these physiochemical characteristics, scETAF/IL-1 was found to be similar, if not identical to human keratinocyte- and macrophage-derived ETAF/IL-1. Further, a number of biologic effects known to occur in vivo after the administration of ETAF/ IL-1, such as fever, neutrophilia, and an increase in plasma levels of acute-phase proteins, were all induced by the injection of scETAF/IL-1 into endotoxin-nonresponsive mice. scETAF/IL1 was also found to stimulate collagenase production by human fibroblasts in vitro. In summary, our studies have established that normal human SC contains a large quantity of SCETAF/IL 1. Whether scETAF/IL-1 integrates into the earliest afferents phases of local inflammatory responses, or merely represents a means of disposal of excessively produced hormone is currently unresolved.
\end{abstract}

\section{Introduction}

A considerable amount of investigative effort has recently been spent on the analysis of interleukin 1 (IL-1), ${ }^{1}$ a hormone that mediates a wide range of biologic effects in vivo and in vitro. IL-1 is a 15,000 -mol wt polypeptide reported to play an integral role in the generation of both immune and inflammatory responses (1-3). Pyrogenicity, neutrophil chemotaxis, lymphocyte activation and chemotaxis, muscle proteolysis, and the production of acute-phase proteins are all effects induced by the action of IL-1 on various anatomic sites including the brain, bone mar-

Address reprint requests to Dr. Daynes.

Received for publication 13 November 1984 and in revised form 28 May 1985

1. Appreviations used in this paper: ETAF, epidermal-derived thymocyte activating factor; IL-1, interleukin 1; LPS, lipopolysaccharide; pI, isoelectric point; PMA, phorbol myristate acetate; SAP, serum amyloid $P$ (substance); SC, stratum corneum.

J. Clin. Invest.

(C) The American Society for Clinical Investigation, Inc.

$0021-9738 / 85 / 10 / 1585 / 07 \$ 1.00$

Volume 76, October 1985, 1585-1591 row, lymphoid tissue, muscle, and liver (4-14). Once believed to be produced only by activated macrophages, the synthesis and secretion of IL-1 or IL-1-like molecules has now been extended to a variety of cell types, including keratinocytes of the skin $(15,16)$. Because of its cellular source, keratinocyte-derived IL-1 was originally termed epidermal-derived thymocyte activating factor (ETAF). However, we now appreciate that ETAF and IL-1 are physiochemically similar and share most biologic activities (17).

Keratinocytes originate in the basal, germinative layer of the epidermis and terminally differentiate to form eventually the cells of the outermost layer of the skin known as the stratum corneum (SC). Dalziel et al. (18) recently established that sterile human SC, implanted intracutaneously into guinea pigs, induced a pronounced inflammatory response suggesting that a pro-inflammatory mediator might associate with this material. Preliminary observations in our laboratory determined that a significant amount of in vitro thymocyte co-stimulator activity was present on the surface of normal human skin. We therefore undertook an investigation to establish whether this bioactivity was associated with substances present within the stratum corneum. Herein we report that normal human stratum corneum contains a large amount of easily extractable ETAF/IL-1 activity. This substance(s) demonstrates the approximate molecular weight, isoelectric points, heat stability, as well as in vitro and in vivo bioactivities of human keratinocyte- and macrophage-derived ETAF/IL-1. The possible biologic implications of this observation are discussed.

\section{Methods}

Experimental animals. $\mathrm{C} 3 \mathrm{H} / \mathrm{HeJ}$ mice and mice of the $\mathrm{C} 57 \mathrm{BL} / 10 \mathrm{ScN}$ strain were bred in our colony from breeding stock originally obtained from the Animal Production Facility, National Institutes of Health. All mice were housed at a maximum density of five animals per $7 \times 11$-in. cage and maintained on Wayne Sterilizable Lab Blox and acidified water ad libitum. Animals of either sex (4-6 wk old) were employed as either a source of murine thymocytes $(\mathrm{C} 3 \mathrm{H} / \mathrm{HeJ})$ or in the in vivo analysis of ETAF/IL-1 (C57BL/10ScN).

Cellular sources of ETAF/IL-1. ETAF/IL-1-containing supernatants were obtained from the transformed keratinocyte cell line PAM 212, which constitutively produces this mediator (19). Cells were cultured at an initial density of $5 \times 10^{5}$ cells $/ \mathrm{ml}$ at $37^{\circ} \mathrm{C}$ with $5 \% \mathrm{CO}_{2}$ in RPMI1640 medium (Hazleton Dutchland, Inc., Denver, PA) containing 5\% fetal calf serum (Sterile Systems Inc., Logan, UT), $50 \mathrm{U} / \mathrm{ml}$ penicillin, $50 \mu \mathrm{g} / \mathrm{ml}$ streptomycin, $2 \mathrm{mM}$ glutamine, $5 \times 10^{-5} \mathrm{M}$ 2-mercaptoethanol and nonessential amino acids (complete RPMI-1640 or cRPMI-1640). After $72 \mathrm{~h}$, supernatants were collected, centrifuged to remove cellular debris, and extensively dialyzed against phosphate-buffered saline (PBS) followed by a final dialysis with RPMI-1640. This PAM 212 supernatant was used as the ETAF/IL-1 standard and was arbitrarily given an activity of $100 \mathrm{U} / \mathrm{ml}$.

Extraction of human SC. SC was obtained from heel callus donated by normal human volunteers. After washing and swabbing the donors' heels with $70 \%$ ethanol, the SC was removed by careful paring with a 
scalpel blade or by using a Dr. Scholl's callus remover. Immediately after collection the SC was snap-frozen in liquid nitrogen and pulverized to a fine powder with a mortar and pestle. The SC was then extracted by adding $10 \mathrm{ml}$ of PBS for each gram of powdered SC, followed by homogenization for $30 \mathrm{~s}$ with a Polytron Tissue Homogenizer (Brinkmann Instruments, Inc., Westbury, NY). The insoluble material was pelleted by centrifugation and the supernatant was collected. This extraction process was then repeated one to four additional times. The protein content of each extract was determined by the Lowry assay using a bovine plasma gamma globulin protein standard (Bio-Rad Laboratories, Richmond, CA). Any deviation from the protocol outlined above is explained in the Results section.

Bioassays employed to detect the presence of ETAF/IL-1 in vitro analysis. The thymocyte co-stimulator assay has become a standard test for the presence of ETAF/IL- 1 and measures the ability of this mediator to augment mitogen-induced proliferation of murine thymocytes. Serial dilutions (in triplicate) of test and standard supernatants were incubated with $5 \times 10^{5}$ peanut agglutinin (Arachis hypogaea, Sigma Chemical Co., St. Louis, MO) negative thymocytes in RPMI-1640 containing $1 \%$ normal mouse serum (plus $5 \mathrm{U} / \mathrm{ml}$ penicillin, $50 \mu \mathrm{g} / \mathrm{ml}$ streptomycin, $2 \mathrm{mM}$ glutamine, $5 \times 10^{-5} \mathrm{M}$ 2-mercaptoethanol and non-essential amino acids) in the presence or absence $2.5 \mu \mathrm{g} / \mathrm{ml}$ of phytohemagglutinin (Sigma Chemical Co.). After $66 \mathrm{~h}$ at $37^{\circ} \mathrm{C}$ in $5 \% \mathrm{CO}_{2}$, cell cultures were pulsed with $0.5 \mu \mathrm{Ci}$ of $\left[{ }^{3} \mathrm{H}\right]$ thymidine $(2 \mathrm{Ci} / \mathrm{mM}$, New England Nuclear, Boston, $\mathrm{MA}$ ) and then harvested $6 \mathrm{~h}$ later onto glass fiber filters ( $\mathrm{PhD}$ cell harvester, Cambridge Technology, Inc., Cambridge, MA).

A second in vitro assay, recently described by Kaye et al. $(20,21)$, employs an ETAF/IL-1-responsive T lymphocyte cell line as a reliable indicator for the presence of ETAF/IL-1 in test and standard supernatants. Serial dilutions, in triplicate, of a supernatant were incubated with 1 $\times 10^{4}$ D10.G4.1 cells in cRPMI- 1640 media containing $5 \%$ fetal calf serum in the presence or absence of $2.5 \mu \mathrm{g} / \mathrm{ml}$ of concanavalin A (Sigma Chemical Co.). Cultures were pulsed with $0.5 \mu \mathrm{Ci}$ of $\left[{ }^{3} \mathrm{H}\right]$ thymidine for the final $6 \mathrm{~h}$ of a 48-h incubation period and harvested, as described above, prior to counting with a scintillation counter (Packard Instrument Co., Inc., Downers Grove, IL).

Neither the $\mathrm{C} 3 \mathrm{H} / \mathrm{HeJ}$ thymocytes nor the D10.G4.1 cells respond significantly to $2.5 \mu \mathrm{g} / \mathrm{ml}$ of mitogen in the absence of ETAF/IL-1 or to the test supernatants (or ETAF/IL-1 standards) in the absence of mitogen. Therefore, both of these in vitro assays measure the ability of ETAF/ IL-1 to augment (or co-stimulate) cellular proliferation induced by mitogen. In our assays, $1 \mathrm{U}$ of ETAF/IL-1 is capable of increasing the proliferative rate of murine thymocytes $10-15$-fold, whereas $1 \mathrm{U}$ of ETAF/ IL-1 induces a 30-50-fold increase in D10.G4.1 cell proliferation.

Co-stimulator activity in any given test supernatant was assigned a unit/milliliter value by comparing it to the ETAF/IL-1 standard. Unit values were calculated by using a formula originally derived by Luger et al. (16): $\mathrm{U} / \mathrm{ml}=100 \times$ (reciprocal dilution of test sample at $30 \%$ maximal $\mathrm{cpm}$ of standard)/(reciprocal of dilution of standard at $30 \%$ maximal cpm of standard).

Collagenase production by human fibroblasts in vitro. The ability of scETAF/IL-1 to stimulate collagenase production by human skin fibroblasts (2-mo-old donor, sixth passage) was assessed employing a procedure described in detail elsewhere (22). Briefly, fibroblasts were grown in a 24-well plate in Dulbecco's modified Eagle's medium containing 10\% fetal calf serum until confluent. $24 \mathrm{~h}$ after confluency the medium was removed and the cells were washed three times with Hank's balanced salt solution. The cells were then incubated for $24 \mathrm{~h}$ at $37^{\circ} \mathrm{C}$ with Dulbecco's medium containing $0.5 \%$ bovine serum albumin alone, or in the presence of $100 \mathrm{U} \mathrm{scETAF} / \mathrm{IL}-1$ or $10 \mathrm{ng} / \mathrm{ml}$ phorbol myristate acetate (PMA, a known stimulator of collagenase activity) (23). After incubation, the medium was removed and collagenase activity was determined after trypsin activation by the soluble fibril assay employing $\left[{ }^{3} \mathrm{H}\right]$ collagen (type 1) from rabbit tendon (22). Under the conditions employed, none of the test preparations was cytotoxic or mitogenic as evidenced by altered DNA content, which was determined by a method described in detail elsewhere (24).
In vivo analysis. ETAF/IL-1 induces a number of characteristic in vivo biologic effects when injected into experimental animals (1-3). We chose to measure three of these effects (temperature elevations, neutrophilia, and an increase in plasma levels of acute-phase proteins). Core body temperature of $\mathrm{C} 57 \mathrm{BL} / 10 \mathrm{ScN}$ mice was determined 20 min postinjection of the test SC extract using a rectal probe and YSI Digital Telethermometer (model 49TA, Fisher Scientific Co., Pittsburgh, PA). Circulating murine neutrophils were quantitated $8 \mathrm{~h}$ postinjection of ETAF/ IL-1-containing preparations by the removal of $50 \mu \mathrm{l}$ of blood from each experimental mouse in heparinized capillary tubes. The total number of leukocytes was determined with a hemocytometer and differential analysis of leukocytes was performed on Wright's stained blood smears. Plasma obtained from mice $24 \mathrm{~h}$ postinjection of the test SC extract was assayed quantitatively for serum amyloid-P (SAP) by radial immunodiffusion employing a rabbit anti-murine SAP antibody.

Physiochemical characterization of IL-1-containing supernatants. $1 \mathrm{ml}$ of a crude SC extract was applied to a $1.6 \times 65-\mathrm{cm}$ column containing ACA 54 (Pharmacia Fine Chemicals, Piscataway, NJ). This column was preequilibrated with Dulbecco's PBS containing $50 \mathrm{U} / \mathrm{ml}$ of penicillin and $50 \mu \mathrm{g} / \mathrm{ml}$ of streptomycin. The column was run at a flow rate of 6.0 $\mathrm{ml} / \mathrm{h}$ and $1.0-\mathrm{ml}$ fractions were collected. $20 \mu \mathrm{l}$ of each column fraction was directly evaluated for ETAF/IL-1 activity in both the D10.G4.1 and thymocyte bioassays.

Chromatofocusing was employed to determine the isoelectric point(s) of the material from human SC extracts having ETAF/IL-1 activity by means of a technique described in detail in the Pharmacia instruction booklet ("Chromatofocusing with Polybuffer and PBE," Pharmacia Fine Chemicals, Uppsala, Sweden). The crude SC extract or the 15,000-mol wt fraction from the ACA 54 column was initially dialyzed against the starting buffer $\left(0.025 \mathrm{M}\right.$ Tris- $\left.\mathrm{CH}_{3} \mathrm{COOH}, \mathrm{pH} 8.3\right)$ followed by its application to a $0.5 \times 30-\mathrm{cm}$ column containing the polybuffer exchanger PBE 94 (Pharmacia Fine Chemicals, Uppsala, Sweden) which was preequilibrated with the starting buffer. A gradient was formed between the pHs of 5 and 8 using the starting and elution buffers recommended for this pH range in the Pharmacia Chromatofocusing instructions. 2-ml fractions were collected and $1-10 \mu$ lof each column fraction was directly tested for ETAF/IL-1 activity using the thymocyte and D10.G4.1 costimulator assays. The protein content of pooled chromatofocusing fractions was determined by employing the Bradford reagent because the polybuffers employed in this procedure interfere with the Lowry assay.

\section{Results}

Analysis of the soluble proteins extracted from SC for ETAF/ $I L-1$ activity in vitro. A cell-free supernatant derived from pooled sequential extractions of a $1 \mathrm{~g}$ sample of SC was tested for the presence of ETAF/IL-1 by the D10.G4.1 and thymocyte costimulator assays. Fig. 1 represents the results obtained using the D10.G4.1 bioassay and demonstrates that the SC extract tested contained a large amount of co-stimulator activity. In terms of units, the SC supernatant possessed $\sim 16,000 \mathrm{U} / \mathrm{ml}$ of ETAF/IL-1 activity or $\sim 4 \times 10^{5} \mathrm{U} / \mathrm{g}$ of original SC. An equivalent amount of co-stimulator activity was detected by the thymocyte bioassay (data not shown). In the absence of mitogen, the supernatant had no stimulatory effect on either the D10.G4.1 cells or murine thymocytes. Protein content in this pooled SC extract was determined by the Lowry assay to be $\sim 1.7 \mathrm{mg} / \mathrm{ml}$. Therefore, $4.3 \mu \mathrm{g}$ of protein (a 1:80 dilution) in the supernatant from SC having ETAF/IL-1 activity (scETAF/IL-1) induced a 60-fold increase in the proliferative rate of the D10.G4.1 cells. These results have been repeated with at least 10 separate $1-\mathrm{g}$ SC samples (each obtained from different human subjects) with only minimal variation in the amount of SCETAF/IL-1 obtained after extraction. Homogenization and extraction of equivalent 


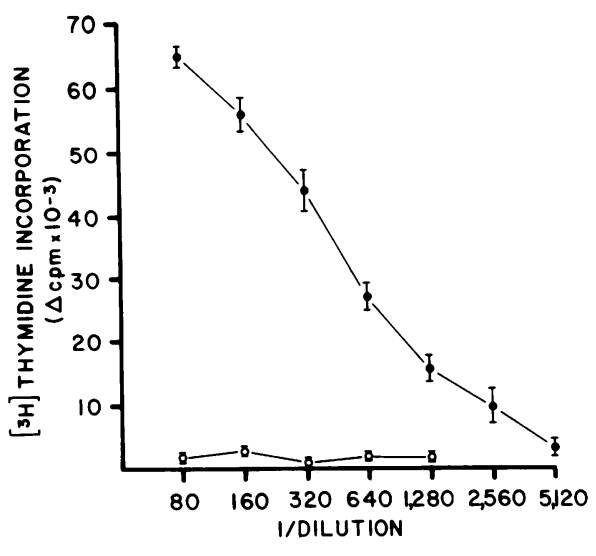

Figure 1. In vitro co-stimulator activity of ScETAF/IL-1. A supernatant derived from the extraction of normal human stratum corneum was tested for in vitro co-stimulator activity employing D10.G4.1 cells for the bioassay (๑). The heat lability of the co-stimulator activity was determined by incubating a parallel sample of this supernatant at $80^{\circ} \mathrm{C}$ for $10 \mathrm{~min}$ before analysis for in vitro activity (O). D10.G4.1 cells responded minimally to $2.5 \mu \mathrm{g} / \mathrm{ml}$ of concanavalin A $(\sim 500$ $\mathrm{cpm}$ ) and this background value was substracted from all experimental values, which are reported as counts per minute. Results are presented as the average \pm the standard error of the mean. Similar results were obtained when thymocytes from lipopolysaccharide (LPS)-nonresponsive mice were employed in the bioassay.

amounts of several other fresh tissues including heart muscle, lung, spleen, and kidney did not yield any ETAF/IL-1 activity.

In an attempt to eliminate the possibility that products from a bacterial contamination in the SC extract were responsible for inducing the cellular proliferation, scETAF/IL-1 was also extracted from a source of SC (vernex) aseptically removed from a newborn infant immediately after delivery by cesarean section. The soluble extract derived from vernex demonstrated a positive co-stimulator activity (data not shown). Further, we found that exposure of scETAF/IL- 1 to $80^{\circ} \mathrm{C}$ for $10 \mathrm{~min}$ before in vitro analysis abrogated all co-stimulator activity (Fig. 1). The results of these experiments suggest that the ETAF/IL-1 activity obtained from SC was not due to bacterial endotoxin contamination because endotoxin is highly resistant to heat inactivation and should not be a contaminate of aseptically collected vernex.

The amount of scETAF/IL-1 and soluble protein that could be obtained from each extraction of a defined amount of SC was determined by a series of sequential treatments. A total of $44 \mathrm{mg}$ of soluble protein and $\sim 7.0 \times 10^{5} \mathrm{U}$ of scETAF/IL-1 could be obtained from a 1.0-g sample of SC (data not shown). The majority of the soluble protein $(87 \%)$ and scETAF/IL-1 activity (93\%) was solubilized from the first two extractions. In order to obtain an equivalent amount of ETAF/IL-1 from conventionally employed ETAF/IL-1-producing cells, one would require a $100 \%$ yield in the recovery of activity from $\sim 7$ liters of tissue culture supernatant. Because the loss of activity through purification and concentration procedures is quite significant $(25,26)$, it is realistic to assume that one would have to start with even greater initial volumes of tissue culture supernatants to derive the amount of ETAF/IL-1 activity that can be easily obtained from a small amount of human SC.

Physiochemical analysis of scETAF/IL-1. A sample of human scETAF/IL-1 was subjected to ACA 54 column chromatography to determine the approximate molecular weight as- sociated with its in vitro co-stimulator activity. The results of this experiment are presented in Fig. 2. All of the scETAF/ IL- 1 bioactivity eluted from the ACA 54 column in fractions that indicate an approximate mol wt of 15,000 . This result is consistent with the reported size of the major species of human ETAF/IL-1 obtained from conventional cell culture sources (1, $25,26)$. In that human IL-2 demonstrates a mol wt of 15,000 and may also possess co-mitogenic activity in vitro, we tested our scETAF/IL-1 on an IL-2-addicted murine T cell line (HT2). We found that neither the unfractionated SC extract nor the 15,000-mol wt molecule(s) derived from this preparation was capable of supporting the proliferation HT2 cells in vitro (data not shown).

Isoelectric point ( $\mathrm{pI}$ ) analysis of human ETAF/IL-1 has suggested that three distinct pI forms exist (7.0-7.2, 6.6-6.8, and $5.0-5.4)(1,25,26)$. The results of our $\mathrm{pI}$ analysis of human scETAF/IL-1 are shown in Fig. 3. Employing a chromatofocusing column set up to separate molecules over a $\mathrm{pH}$ range of between 8 and 5 , three $\mathrm{pI}$ forms $(7.2,6.6$, and 5.0) of co-stimulator activity eluted from the column. Results obtained by directly testing column fractions in the D10.G4.1 bioassay suggests that the major peak of co-stimulator activity has a pI of 7.2. However, when peaks of activity were pooled separately and dialyzed to remove the chromatofocusing buffers, an equivalent amount of co-stimulator activity was present in each of the peaks (data not shown).

The data presented in Table I represent the scheme employed to semipurify scETAF/IL-1 from a 1.0-g sample of normal SC. Dialysis of the crude SC extract against a low molarity Tris-

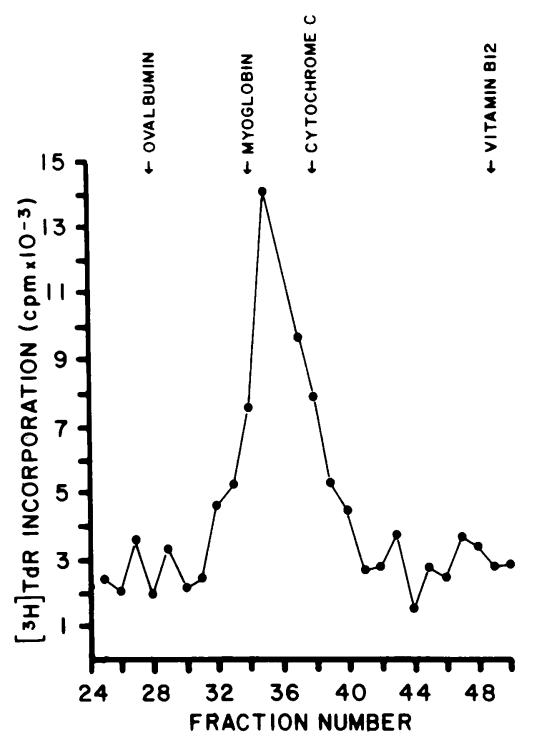

Figure 2. Determination of the approximate molecular weight of scETAF/IL-1. A 1-ml sample of SC extract demonstrating in vitro costimulator activity $(\sim 1000 \mathrm{U} / \mathrm{ml})$ was subjected to column chromatography as described in Methods. The molecular weight standards employed were ovalbumin $(44,000)$, myoglobin $(18,800)$, cytochrome $c(12,384)$ and vitamin $B_{12}(1,355)$. 1-ml column fractions were collected and $20 \mu \mathrm{l}$ of each fraction (in triplicate) was tested directly for in vitro co-stimulator activity employing D10.G4.1 cells. Similar results were obtained employing LPS-nonresponsive thymocytes for the bioassay. This elution profile corresponds to the profile obtained when supernatant from an ETAF/IL-1 producing human cell line (A431) was chromatographed. 




Figure 3. pI analysis of scETAF/IL-1. 1,000 U of scETAF/IL-1 was subjected to chromatofocusing between the range of $\mathrm{pH} 8$ and $5(\Delta)$. $1-\mathrm{ml}$ fractions were collected and $5 \mu \mathrm{l}$ of each fraction (in triplicate) was analyzed directly for in vitro co-stimulator activity employing D10.G4.1 cells. Co-stimulator activity is represented as counts per minute (๑). Peaks with co-stimulator activity were pooled separately and dialyzed against RPMI-1640 before retesting. All three peaks (pH 7.2, 6.6, and 5.0) contained equivalent amounts of co-stimulator activity after dialysis (data not shown). Human ETAF/IL-1 from a human cell line (A431) subjected to $\mathrm{pI}$ analysis employing this technique also demonstrated three $\mathrm{pI}$ forms corresponding to $\mathrm{pH}$ 5.0-5.2, 6.66.8 , and 7.0-7.2.

containing buffer resulted in the spontaneous precipitation of the majority of protein. Keratohyalins found in SC are reported to precipitate under these conditions (27). Our results demonstrate that the specific activity of scETAF/IL-1 increases throughout the procedures employed for purification except the molecule(s) with the lowest pI. The $\mathrm{pH}$ range employed for the chromatofocusing was apparently not optimal for separation of

Table I. Extraction and Semipurification of scETAF/IL-1

\begin{tabular}{|c|c|c|c|}
\hline & $\begin{array}{l}\text { Total proteinf } \\
\text { recovered }\end{array}$ & $\begin{array}{l}\text { Total activity§ } \\
\text { recovered }\end{array}$ & $\begin{array}{l}\text { ETAF/IL-1" } \\
\text { activity }\end{array}$ \\
\hline & $m g$ & $U$ & $U / m g$ of protein \\
\hline Saline SC extract* & 134.0 & $6.0 \times 10^{5}$ & $4.4 \times 10^{3}(1) \pi$ \\
\hline \multicolumn{4}{|l|}{ Dialysis $(0.025 \mathrm{M}$} \\
\hline Tris) & 41.0 & $7.0 \times 10^{5}$ & $1.8 \times 10^{4}(4)$ \\
\hline \multicolumn{4}{|l|}{ Gel filtration } \\
\hline chromatography & 10.0 & $6.5 \times 10^{5}$ & $6.1 \times 10^{4}(14)$ \\
\hline \multicolumn{4}{|l|}{ Chromatofocusing } \\
\hline pH 7.0-7.2 & 0.160 & $7.4 \times 10^{4}$ & $4.6 \times 10^{5}(104)$ \\
\hline pH 6.0-6.8 & 0.105 & $2.2 \times 10^{4}$ & $2.1 \times 10^{5}(48)$ \\
\hline pH $5.0-5.2$ & 0.225 & $2.4 \times 10^{3}$ & $1.0 \times 10^{4}(2)$ \\
\hline
\end{tabular}

* $1 \mathrm{~g}$ of normal human SC was snap-frozen with liquid nitrogen and ground into a fine powder with mortar and pestle. ScETAF/IL-1 was extracted with PBS as described in Methods.

$\ddagger$ The protein content of test preparations was determined by either the Lowry or Bradford assay.

$\S$ In vitro co-stimulator activity was determined using the D10.G4.1 cell line.

"Specific activity represents the total activity recovered divided by the total protein recovered.

I The numbers in parentheses represent the specific activity of each following procedure divided by the starting specific activity. the pI 5.0 molecule from other contaminating peptides. Exhaustive treatment of the $15,000-\mathrm{mol} \mathrm{wt}(\mathrm{pI} 7.2-7.0)$ preparation of scETAF/IL-1 with insoluble trypsin resulted in the loss of the majority (70\%) of the co-stimulator activity (data not shown). Insoluble chymotrypsin was less effective, however it also resulted in a decrease in the bioactivity.

Biologic effects of scETAF/IL-1 in vivo. Our in vitro analysis indicated that the physiochemical characteristics of scETAF/ IL-1 were similar if not identical to ETAF/IL-1 obtained from conventional cell sources. This conclusion, however, was based on the accuracy of the murine thymocyte and the D10.G4.1 bioassay to define the presence of ETAF/IL-1. We are aware that problems may arise with this interpretation, because it has been previously demonstrated by others that certain serum and cellular proteases (28) or phorbol esters (29) are capable of interfering with these in vitro bioassays.

IL-1 has classically been defined by its in vivo biologic effects. Pyrogenicity $(4,30)$, neutrophilia $(5)$, acute-phase protein synthesis $(13,14)$, muscle proteolysis $(11,12)$, prostaglandin synthesis $(31,32)$, collagenase production $(33,34)$ and several other effects have been demonstrated to be induced by IL-1 $(35,36)$. The following experiment was conducted to determine whether scETAF/IL-1 exhibits in vivo stimulatory activity on a number of diverse IL-1 sensitive targets. A defined amount (established by in vitro analysis) of scETAF/IL-1 was injected intravenously into $\mathrm{C} 57 \mathrm{BL} / 10 \mathrm{ScN}$ mice which are genetically nonresponsive to lipopolysaccharide. Core body temperature was analyzed after $20 \mathrm{~min}$ and found to be elevated (a response that returned to normal by $2 \mathrm{~h}$ ), blood samples were collected after $8 \mathrm{~h}$ and found to contain elevated numbers of circulating neutrophils, and plasma samples, collected after $24 \mathrm{~h}$, determined that the circulating level of SAP, a major murine acute-phase protein, was significantly elevated (Table II). Pretreatment of the scETAF/ IL-1 with heat $\left(80^{\circ} \mathrm{C}\right.$ for $\left.10 \mathrm{~min}\right)$ before intravenous injection abrogated all in vivo bioactivity. A $15,000-\mathrm{mol}$ wt preparation (by ACA column chromatography) of scETAF/IL-1 was also capable of eliciting each of these in vivo biologic effects. Clearly, scETAF/IL-1 exhibits biologic identity with human ETAF/ IL-1 by its ability to elevate core body temperature (pyrogenicity), increase the number of circulating neutrophils (neutrophil-releasing activity), and elevate the concentration of an acute-phase protein (induction of acute-phase protein activity).

The heterogeneous nature of the $\mathrm{pI}$ forms of ETAF/IL- 1 has been the subject of several recent reports. This heterogeneous nature is not due to differences in the glycosylation of the molecule (37) and each of the human $\mathrm{pI}$ forms has been reported to possess equivalent in vitro and in vivo biologic activity (38). When a defined amount of each of the isolated $\mathrm{pI}$ forms of scETAF/IL-1 was injected into groups of C57BL/10ScN mice, an elevation in core body temperature, peripheral blood neutrophils, and SAP concentrations were observed (Table II).

Stimulation of collagenase production in vitro. The possible biologic relevance of scETAF/IL-1 in normal human SC is presently unknown; however, in light of the known properties of this mediator, one could speculate that it may integrate into the earliest events following wounding of the skin. One of the properties of ETAF/IL-1 is its ability to induce the production of collagenase by fibroblasts (31-34), an event associated with inflammation. We investigated the ability of scETAF/IL-1 to induce collagenase production by cultured human skin fibroblasts. The results shown in Fig. 4 demonstrate that the 15,000-mol wt 
Table II. In Vivo Biologic Effects of scETAF/IL-1

\begin{tabular}{|c|c|c|c|c|}
\hline \multirow[b]{2}{*}{ scETAF/IL-1 } & \multirow[b]{2}{*}{ Unitsł injected } & \multicolumn{3}{|l|}{ Biologic effect } \\
\hline & & $\Delta$ Temperature§ & $\Delta$ Neutrophils" & $\Delta$ SAPI \\
\hline & & ${ }^{\circ} \mathrm{C}$ & $\times 10^{-5} \mathrm{cells} / \mathrm{ml}$ & $\mu g / m l$ \\
\hline \multirow[t]{3}{*}{ Whole SC extract* } & 875 & $0.7 \pm 0.10^{* *}$ & $16.8 \pm 1.4$ & $44 \pm 2.0$ \\
\hline & $875\left(10 \mathrm{~min}, 80^{\circ} \mathrm{C}\right)$ & $0.1 \pm 0.12$ & $1.4 \pm 1.3$ & $4 \pm 3.0$ \\
\hline & 175 & $0.3 \pm 0.09$ & $4.8 \pm 1.0$ & $38 \pm 6.8$ \\
\hline $15,000-\mathrm{mol}$ wt fraction & 375 & $0.8 \pm 0.13$ & $12.2 \pm 0.6$ & $41 \pm 5.4$ \\
\hline 15,000 -mol wt (pI 7.0-7.2) & 250 & $0.6 \pm 0.05$ & $10.6 \pm 1.3$ & $38 \pm 10$ \\
\hline $15,000-\mathrm{mol} w \mathrm{wt}(\mathrm{pI} 6.6-6.8)$ & 250 & $0.3 \pm 0.04$ & $8.9 \pm 1.4$ & $107 \pm 14$ \\
\hline $15,000-\mathrm{mol} \mathrm{wt}$ (pI 5.0-5.2) & 250 & $0.4 \pm 0.03$ & $8.3 \pm 1.3$ & $30 \pm 5$ \\
\hline
\end{tabular}

* Groups of five C57BL/10ScN mice were employed for each experimental stratum corneum preparation. Control animals were injected with an equivalent volume of physiologic saline. ‡ Determined using the thymocyte proliferation assay and the D10.G4.1 co-stimulator assay. § Rectal temperature taken at $20 \mathrm{~min}$ after intravenous injection. "Neutrophils were quantitated on blood samples taken $8 \mathrm{~h}$ after the intravenous injection of scETAF/IL-1 or saline. I SAP was quantitated by radial immunodiffusion. ** All results represent the mean \pm standard error of the mean.

scETAF/IL-1 and each of the pI forms of this mediator was capable of inducing collagenase production by human fibroblasts. Human skin fibroblasts constitutively produce collagenase activity $\left(4.4 \mathrm{U} / 10^{6}\right.$ cells) when assayed at confluency in serumfree medium. PMA, a known potent stimulator of collagenase (22), increased the enzyme activity twofold. Similarily, all preparations of scETAF/IL- 1 at a concentration of $100 \mathrm{U} / \mathrm{ml}$ ) elicited a $50 \%$ increase over control values in the rate of collagenase production.

\section{Discussion}

The epidermis of skin is predominately composed of keratinocytes. These cells originate from rapidly dividing precursors in

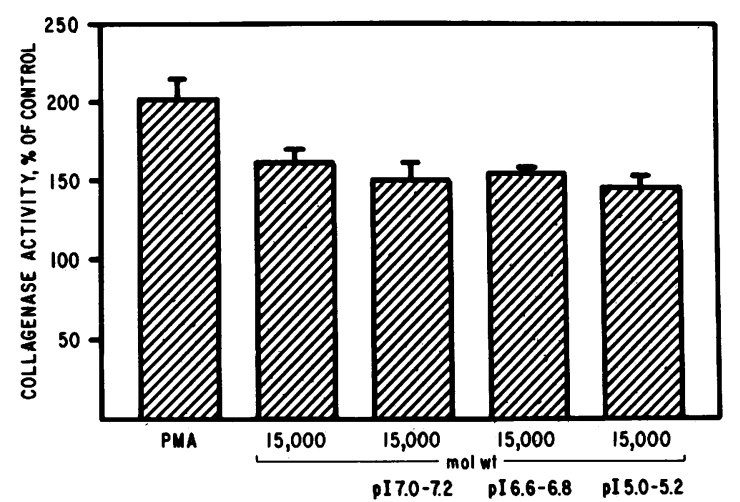

Figure 4. Stimulation of human fibroblast skin collagenase by scETAF/IL-1. Confluent fibroblast cultures were treated for $24 \mathrm{~h}$ with PMA (10 ng/ml), $100 \mathrm{U} / \mathrm{ml}$ of 15,000 -mol wt scETAF/IL, $100 \mathrm{U} / \mathrm{ml}$ of 15,000-mol wt (pI 7.0-7.2), $100 \mathrm{U} / \mathrm{ml}$ of 15,000-mol wt (pl 6.6-

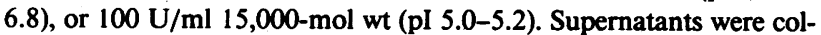
lected and tested for collagenase activity (after trypsin activation) by the soluble fibril assay employing $50 \mu \mathrm{g}$ of $\left[{ }^{3} \mathrm{H}\right]$ collagen (type 1). Collagenase activity in supernatants from control fibroblast culture induced the degradation of $14.7 \pm 0.4 \mu \mathrm{g}$ of $\left[{ }^{3} \mathrm{H}\right]$ collagen during the $1-\mathrm{h}$ incubation period. The activity in supernatants from test cultures is expressed as percent increase over control \pm standard error of the mean. All scETAF/IL-1 preparations as well as the PMA stimulated collagenase activity significantly above controls $(P<0.001)$. the basal layer and migrate peripherally during their differentiation to eventually form the SC (39). During this migration process the keratinocytes gain and lose a number of characteristics and functions that associate with their precise anatomic location (39). Although we now appreciate the immunologic potential of other resident cell types within the epidermis, such as the Langerhans cell, only recently have the keratinocyte and its products been implicated as an active participant in the generaiton of both immune and inflammatory responses $(40,41)$. Keratinocyte expression of class II molecules of the major histocompatibility complex can be induced or is associated with certain experimental and pathologic conditions (42-44). It has recently been suggested that expression of these molecules serves to facilitate the migration of lymphoid cells into the skin (manuscript submitted for publication). In 1982, Sauder et al. (15) and Luger et al. (16) observed that keratinocytes can produce a molecule termed the "epidermal-derived thymocyte activating factor" (ETAF), which was similar in function and physiochemical characteristics to macrophage derived IL-1 (17). It is now appreciated that keratinocytes represent the major producers of this polypeptide hormone in the skin. We have previously reported that normal keratinocytes produce a significant amount of ETAF/IL-1 constitutively when maintained in vitro (45). It is also appreciated that ETAF/IL-1 production can be augmented by the addition of exogenous inducers of inflammation to cell cultures or by exposure of keratinocytes to the effects of ultraviolet radiation in vitro $(15-17,45)$. Furthermore, the exposure of animals to ultraviolet radiation in vivo results in a pronounced inflammatory response, which is accompanied by an elevation in peripheral blood neutrophils, an increase in the plasma concentration of several acute phase proteins, and the presence of detectable levels of ETAF/IL-1 in the serum (45).

It has been observed that subcutaneous implantation of sterile human SC into guinea pigs results in a marked inflammation which is followed by granuloma formation (18). Therefore, the object of this investigation was to determine whether the underlying mechanism(s) responsible for this inflammatory response might be due to the presence of preformed pools of ETAF/ IL-1 within the SC inoculum. Our experiments demonstrate that the extraction of $\mathrm{SC}$ with physiologic saline yields a soluble pro- 
tein-containing supernatant having significant ETAF/IL-1 activity. scETAF/IL-1 was assessed in vitro by its ability to costimulate the proliferation of both a cloned IL-1-responsive murine T-cell line as well as murine thymocytes derived from LPS. nonresponsive donors. Further support for the concept that scETAF/IL-1 and ETAF/IL-1 were similar was obtained when the co-stimulator activity demonstrated heat lability, molecular weight, and isoelectric points that were consistent with the properties of keratinocyte- and macrophage-derived human ETAF/ IL-1 (1). Our results also demonstrate that scETAF/IL-1 and each of the isoelectric forms of this mediator are capable of inducing a significant increase in collagenase production by normal human fibroblasts in vitro.

IL-1 has been functionally defined by its ability to stimulate a variety of target-cell specific responses in vivo (4-14). These include pyrogenicity, the ability to induce neutrophilia, and the stimulation of liver hepatocytes to produce acute-phase proteins. We established that each of these effects could be induced by the injection of scETAF/IL-1 into LPS non-responsive mice. Further, the kinetics of the scETAF/IL-1-induced effects was consistent with their being mediated by ETAF/IL-1 and not an unknown exogenous stimulant. Therefore, the results obtained from both in vivo and in vitro analysis of SC extracts suggest that a molecule is present in SC, which funcitonally and physiochemically is similar to human ETAF/IL-1.

The SC is known to serve many homeostatic functions including the ability to absorb ultraviolet radiation from the sun, retain water within the body, and act as a major diffusion barrier to prevent potentially toxic molecules from gaining entrance. Percutaneous absorption studies have demonstrated that small lipophilic molecules can readily penetrate through SC and gain entrance to the circulation whereas the penetration of ionic molecules is greatly impeded. Increasing the hydration of SC, exposure of skin to ultraviolet radiation, or topical application of a number of substances can increase the rate of percutaneous absorption (46). It has also been demonstrated that SC has the capacity to act as a reservoir for some lipid-soluble molecules $(47,48)$. For example, the topical application of hydrocortisone results in the slow release of this substance for as long as $7 \mathrm{~d}$, an effect that can be abrogated by stripping the skin of stratum corneum (47).

The amount of scETAF/IL-1 that can be extracted from SC might suggest that this structure is functioning as a reservoir of this mediator (in either secreted or membrane-associated form). Recent evidence from our laboratory suggests that normal keratinocytes appear to express ETAF/IL-1 constitutively on their plasma membrane surface (Gahring and Daynes, manuscript in preparation). If we hypothesize that keratinocytes constitutively produce this mediator (or constitutively express membrane-associated forms), the presence of scETAF/IL-1 may represent a means by which excesses of this hormone are externalized. Other investigators have also been interested in the means by which IL-1 is removed from the body. Kimball et al. (49) have recently demonstrated that small quantities of IL-1 (ETAF/IL-1) could be detected in normal human urine after concentration and dialysis. Therefore, passage through the kidneys followed by excretion may represent a means by which IL-1 is externalized. The body is also capable of removing substances via sweat. We have preliminary evidence to suggest that human sweat contains a significant co-stimulator activity when tested in vitro after extensive dialysis. This co-stimulator activity may in fact be
scETAF/IL-1 derived from the hydration and release from the SC. The spontaneous elution of scETAF/IL-1 into fluid medium may also be responsible for our observation that in vitro costimulator activity could be detected in normal amniotic fluid obtained from a number of individuals (unpublished observations). The amount of co-stimulator activity obtained from the extraction of normal human stratum corneum far exceeds any activity obtained from urine, sweat, or amniotic fluid and may represent a major site of ETAF/IL-1 disposal.

Considering the quantity of scETAF/IL-1 found in stratum corneum, several intriguing possibilities for a functional role for this molecule in wound healing could be hypothesized. Immune potentiating, chemotactic (neutrophil and T-lymphocyte), and autocrine functions of IL-1 have all been described (50). Further, IL-1 is known to induce fibroblasts to produce collagenase and E-series prostaglandins $(31-34)$. If scETAF/IL-1 is released into a local site after wounding, inflammatory and immune processes known to require IL-1 could be immediately initiated without the lag period required for the de novo synthesis and release of this mediator by viable cells. Whether scETAF/IL-1 proves to be the inflammatory mediator responsible for the effects observed after the subcutaneous implantation of human SC into guinea pigs awaits further experimentation. The large amount of ETAF/ IL-1 activity present in normal SC, coupled with the knowledge that this mediator is a known and essential inducer of inflammatory responses, indicates that ScETAF/IL-1 and its potential involvement in homeostatic mechanisms warrant further investigation.

\section{Acknowledgment}

This research was supported by grants CA-33065 and CA-22126 awarded by the National Cancer Institute, plus research funds from Cooper Biomedical, Palo Alto, CA.

\section{References}

1. Luger, T. A., and J. J. Oppenheim. 1983. Characteristics of interleukin-1 and epidermal cell-derived thymocyte activating factor. $A d v$. Inflammation Res. 5:1-25.

2. Oppenheim, J. J., B. M. Stadler, R. P. Siraganian, M. Mage, and B. Mathieson. 1982. Lymphokines: their role in lymphocyte responses; Properties of interleukin-1. Fed. Proc. 41:257-262.

3. Powanda, M. C., and W. R. Beisel. 1982. Hypothesis: leukocyte endogenous mediator/endogenous pyrogen/lymphocyte activating factor modulates the development of nonspecific and specific immunity and affects nutritional status. Am. J. Clin. Nutr. 35:762-768.

4. Dinarello, C. A., and S. M. Wolf. 1982. Molecular basis of fever in humans. Am. J. Med. 72:799-819.

5. Merriman, C. R., L. A. Pulliam, and R. F. Kampschmidt. 1977. Comparison of leukocytic pyrogen and leukocyte endogenous mediator. Proc. Soc. Exp. Biol. Med. 154:224-227.

6. Luger, T. A., J. A. Charon, M. Colot, M. Micksche, and J. J. Oppenheim. 1983. Chemotactic properties of partially purified human epidermal cell-derived thymocyte activating factor (ETAF) for polymorphonuclear and mononuclear cells. J. Immunol. 131:816-820.

7. Gery, I., R. K. Gershon, and B. H. Waksman. 1971. Potentiation of cultured mouse thymocyte responses by factors released by peripheral leukocytes. J. Immunol. 107:1778-1785.

8. Gillis, S. 1983. Interleukin biochemistry and biology: summary and introduction. Fed. Proc. 42:2635-2645.

9. Miossec, P., Chia-Li Yu, and M. Ziff. 1984. Lymphocyte chemotactic activity of human interleukin-1. J. Immunol. 133:2007-2011.

10. Sauder, D. N., M. Monick, and G. Hunninghake. 1984. Human 
epidermal cell derived thymocyte activating factor is a potent T-cell chemoattractant. J. Invest. Dermatol. 82:399. (Abstr.)

11. Baracos, V., H. P. Rodemann, C. A. Dinarello, and A. L. Goldberg. 1983. Stimulation of muscle protein degradation and prostaglandin E release by leukocytic pyrogen (IL-1). A mechanism for the increased degradation of muscle proteins during fever. N. Engl. J. Med. 308:553558.

12. Clowes, G. H. A., B. C. George, C. A. Villee, and C. A. Saravis. 1983. Muscle proteolysis induced by a circulating peptide in patients with sepsis or trauma. N. Engl. J. Med. 308:544-552.

13. Dinarello, C. A. 1984. Induction of acute phase reactants by interleukin-1. Adv. Inflammation Res. 8:203-225.

14. Baumann, H., G. P. Jahreis, D. N. Sauder, and A. Koj. 1984. Human keratinocytes and monocytes release factors which regulate the synthesis of major acute plasma proteins in hepatic cells from man, rat, and mouse. J. Biol. Chem. 259:7331-7342.

15. Sauder, D. N., C. S. Carter, S. I. Latz, and J. J. Oppenheim. 1982. Epidermal cell production of thymocyte activating factor (ETAF). J. Invest. Dermatol. 79:34-39.

16. Luger, T. A., B. M. Stadler, S. I. Katz, and J. J. Oppenheim. 1981. Epidermal cell (keratinocyte)-derived thymocyte-activating factor (ETAF). J. Immunol. 127:1493-1498.

17. Luger, T. A., B. M. Stadler, B. M. Luger, B. J. Mathieson, M. Mage, J. A. Schmidt, and J. J. Oppenheim. 1982. Murine epidermal cell derived thymocyte activating factor resembles murine interleukin- $1 . J$. Immunol. 128:2147-2152.

18. Dalziel, K., P. J. Dykes, and R. Marks. 1984. Inflammation due to intra-cutaneous implantation of stratum corneum. Br. J. Exp. Pathol. 65:107-115.

19. Yuspa, S. H., P. Hawley-Nelson, B. Koehler, and J. R. Stanely. 1980. A survey of transformation markers in differentiating epidermal cell lines in culture. Cancer Res. 40:4694-4703.

20. Kaye, J., J. Porcelli, B. Tite, B. Jones, and C. A. Janeway. 1983. Both a monoclonal antibody and antisera specific for determinants unique to individual cloned helper $\mathrm{T}$ cell lines can substitute for antigen and antigen presenting cells in the activation of T-cells. J. Exp. Med. 158: 836-856.

21. Kaye, J., and C. A. Janeway. 1984. The FAB fragment of a directly activating monoclonal antibody that precipitates a disulfide-linked heterodimer from a helper T-cell clone blocks activating by either allogeneic Ia or antigen and self Ia. J. Exp. Med. 159:1397-1412.

22. Seng, W. L., P. F. Davison, and K. R. Kenyon. 1984. A simple vertebrate collagenase assay using soluble radioactive collagen substrate. Anal. Biochem. 139:17-24.

23. Brinkerhoff, C. E., R. M. McMillan, J. V. Fahey, and E. D. Harris. 1979. Collagenase production by synovial fibroblasts treated with phorbol myristate actate. Arthritis Rheum. 22:1109-1116.

24. Johnson-Wint, B., and S. Hollis. 1982. A rapid in situ deoxyribonucleic acid assay for determining cell number in culture and tissue. Anal. Biochem. 122:338-344.

25. Lachman, L. B., S. O. Page, and R. S. Metzgar. 1980. Purification of human interleukin-1. J. Supramol. Struct. 13:457-466.

26. Schmidt, J. A. 1984. Purification and partial biochemical characterization of normal human interleukin-1. J. Exp. Med. 160:772-787.

27. Berstein, I. A. 1983. The proteins of keratohyalin. In Biochemistry and Physiology of the Skin, Vol. I. L. A. Goldsmith, editor. Oxford University Press, London 170-183.

28. Katz, S. P., T. Shimamura, J. P. Dessaint, D. Braverman, and B. H. Waksman. 1980. Mechanisms of action of lymphocyte activating factor (LAF). IV. Differential stimulation of T-lymphocytes by induced macrophage enzymes (catheptic carboxypeptidase B and serine proteases). J. Immunol. 122:2173-2179.

29. Krakauer, T., D. Mizel, and J. J. Oppenheim. 1982. Independent and synergistic thymocyte proliferative activities of PMA and IL-1. $J$. Immunol. 129:939-941.
30. Bodel, P., and H. Miller. 1977. Differences in pyrogen production by mononuclear phagocytes and by fibroblasts or HeLa cells. J. Exp. Med. 145:607-617.

31. Dayer, J., S. M. Krane, R. G. G. Russell, and D. R. Robinson. 1976. Production of collagenase and prostaglandins by isolated adherent rheumatoid synovial cells. Proc. Natl. Acad. Sci. USA. 73:945-949.

32. Dayer, J., D. R. Robinson, and S. M. Krane. 1977. Prostaglandin production by rheumatoid synovial cells. Stimulation by a factor from human mononuclear cells. J. Exp. Med. 145:1399-1404.

33. Postlethwaite, A. E., L. B. Lachman, C. L. Mainardi, and A. H. Kang. 1983. Interleukin-1 stimulation of collagenase production by cultured fibroblasts. J. Exp. Med. 157:801-806.

34. Mizel, S. B., J. M. Dayer, S. M. Krane, and S. E. Mergenhagen. 1981. Stimulation of rheumatoid synovial cell collagenase and prostaglandin production by partially purified lymphocyte-activating factor (IL-1). Proc. Natl. Acad. Sci. USA. 78:2474-2477.

35. Gowen, M., D. D. Wood, E. J. Ihrie, M. K. B. McGuire, and R. G. G. Russell. 1983. An interleukin 1-like factor stimulates bone resorption in vitro. Nature (Lond.) 306:378-380.

36. Schmidt, J. A., S. B. Mizel, D. Cohen, and I. Green. 1982. Interleukin-1, a potential regulator of fibroblast proliferation. J. Immunol. 128:2177-2182.

37. Krakauer, T. 1984. Structural analysis of the charge heterogeneity of human interleukin 1. Arch. Biochem. Biophys. 234:371-376.

38. Wood, D. D., E. K. Bayne, M. B. Goldring, M. Gowen, D. Hamerman, J. L. Humes, E. J. Ihrie, P. E. Lipsky, and M.-J. Staruch. 1985. The four biochemically distinct species of human interleukin 1: all exhibit similar biologic activities. J. Immunol. 134:895-903.

39. Odland, G. F. 1983. Structure of the skin. In Biochemistry and Physiology of the Skin, Vol. I. L. A. Goldsmith, editor. Oxford University Press, London. 3-63.

40. Sauder, D. N., C. A. Dinarello, and V. B. Morhenn. 1984. Langerhans cell production of interleukin-1. J. Invest. Dermatol. 82:605607.

41. Sauder, D. N., and S. I. Katz. 1982. Immune modulation by epidermal products: possible role of ETAF in inflammatory and neoplastic skin diseases. J. Am. Acad. Dermatol. 7:651-654.

42. Lampert, I. A., A. J. Suitters, and P. M. Chisholm. 1981. Expression of la antigen on epidermal keratinocytes in graft-versus-host disease. Nature (Lond.). 291:149-150.

43. Daynes, R. A., M. Emam, G. G. Krueger, and L. K. Roberts. 1983. Expression of Ia antigen on epidermal keratinocytes after the grafting of normal skin to nude mice. J. Immunol. 130:1536-1539.

44. Roberts, L. K., M. Emam, R. A. Daynes, and G. G. Krueger. 1984. Inducible expression of Ia by keratinocytes in vivo and in vitro: cellular and humoral components. Clin. Res. 32:482A. (Abstr.)

45. Gahring, L. C., M. Balz, M. B. Pepys, and R. A. Daynes. 1984. The effect of ultraviolet radiation on the production of ETAF/IL-1 in vivo and in vitro. Proc. Natl. Acad. Sci. USA. 81:1198-1202.

46. Scheuplein, R. J., and R. L. Bronaugh. 1983. Percutaneous Absorption. In Biochemistry and Physiology of the Skin, Vol. II. L. A Goldsmith, editor. Oxford University Press, London. 1255-1295.

47. Malkinson, F. D., and E. H. Ferguson. 1955. Preliminary and short report. Percutaneous absorption of hydrocortisone-4-C14 in two human subjects. J. Invest. Dermatol. 25:281-283.

48. Vickers, C. F. H. 1963. Existence of reservoir in the stratum corneum. Arch. Dermatol. 88:21-23.

49. Kimball, E. S., S. A. Pickerall, J. J. Oppenheim, and J. L. Rossio. 1984. Interleukin 1 activity in normal human urine. J. Immunol. 133 256-260.

50. Gilchrest, B. A., and D. N. Sauder. 1984. Autocrine growth stimulation of human keratinocytes by epidermal cell-derived thymocyte activating factor (ETAF), implications for cellular aging. J. Invest. Dermatol. 82:439. (Abstr.) 